\title{
Obtaining Optimal Solution by Using Very Good Non-Basic Feasible Solution of the Transportation and Linear Programming Problem
}

\author{
R. R. K. Sharma \\ Department of Industrial and Management Engineering, Indian Institute of Technology, Kanpur, India \\ Email: rrks@iitk.ac.in
}

How to cite this paper: Sharma, R.R.K. (2017) Obtaining Optimal Solution by Using Very Good Non-Basic Feasible Solution of the Transportation and Linear Programming Problem. American Journal of Operations Research, 7, 285-288. https://doi.org/10.4236/ajor.2017.75021

Received: June 21, 2017

Accepted: August 29, 2017

Published: September 1, 2017

Copyright $\odot 2017$ by author and Scientific Research Publishing Inc. This work is licensed under the Creative Commons Attribution-NonCommercial International License (CC BY-NC 4.0). http://creativecommons.org/licenses/by-nc/4.0/ cc) (i) (8) Open Access

\begin{abstract}
For the transportation problem, Sharma and Sharma [1] have given a very computationally efficient heuristic (runs in $\mathrm{O}\left(\mathrm{c}^{\star} \mathrm{n}^{2}\right)$ time) to give very good dual solution to transportation problem. Sharma and Prasad [2] have given an efficient heuristic (complexity $\mathrm{O}\left(\mathrm{n}^{3}\right)$ procedure to give a very good primal solution (that is generally non-basic feasible solution) to transportation problem by using the very good dual solution given by Sharma and Sharma [2]. In this paper we use the solution given by Sharma and Prasad [2] to get a very good Basic Feasible Solution to transportation problem, so that network simplex (worst case complexity $\left(\mathrm{O}\left(\mathrm{n}^{3 *}(\log (\mathrm{n}))\right)\right.$ can be used to reach the optimal solution to transportation problem. In the second part of this paper, we give a simple heuristic procedure to get a very good BFS to linear programming problem from the solution given by Karmarkar [3] (that generally produces a very good non-basic feasible solution in polynomial time $\left(\mathrm{O}\left(\mathrm{n}^{5.5}\right)\right)$. We give a procedure to obtain a good BFS for LP by starting from the solution given by Karmarkar [3]. We note that this procedure (given here) is significantly different from the procedure given in [4].
\end{abstract}

\section{Keywords}

Optimal BSF Solution, Transportation Problem, Linear Programming Problem

\section{Introduction}

\subsection{For Transportation Problem}

Sharma and Prasad [2] gave a very good non-basic primal solution to the trans- 
portation problem. We give a procedure (named as PNP-1) here to make use of this (this non-basic feasible solution to get a good basic feasible solution). This enables Network Simplex to lead to optimality by making use of advanced start.

\subsection{For Linear Program}

Similarly, Karmarkar [3] gives a very good interior point solution to Linear Program in polynomial time. We give a procedure (PNP 2) to get very good BFS for Linear program (by using solution given in [3]). And this enables Simplex Procedure to lead to optimality by making use of this advanced start.

\section{Formulation of Transportation Problem}

Problem P1.

$$
\min \sum_{k} \sum_{i} X_{i k} \cdot C_{i k}
$$

s.t.

$$
\begin{gathered}
\sum_{i} X_{i k}=d_{k} \text { for all } k=1, \cdots, K \\
\sum_{k} X_{i k}=b_{i} \text { for all } i=1, \cdots, I \\
X_{i k} \geq 0 \text { for all } i \text { and } k
\end{gathered}
$$

For the balanced transportation problem, method due to Sharma and Prasad [2] gives a very good feasible solution with exactly "p" $X_{i k}>0$. It is to be noted that in a BFS exactly $K+I-1, X_{i k}$ need to be greater than zero.

\section{The Proposed New Procedure PNP 1}

\section{PNP 1}

Step 1: Prepare a list L of "p" $C_{i k}$ such that $X_{i k}$ 's $>0$.

Then sort ("p") $C_{i k}$ 's with $X_{i k}$ 's $>0$ in increasing order. Put first $K+I-1$ items of L in list L1 and remaining $C_{i k}$ 's with $X_{i k}{ }^{\prime} \mathrm{s}>0$ in list L2. It is to be noted that the associated cells in L1 form a basis.

Step 2: Then we take first item from L2. It can be easily seen that cells of $\mathrm{L} 1+$ first cell $\left(\mathrm{CE}^{\star}\right)$ taken out of $\mathrm{L} 2$ has a unique cycle. Perform the pivot operation to determine the leaving cell (by using $C_{i k}$ 's as relative cost co-efficients. It can be seen that resulting partial solution may increase or decrease.

Step 3: Remove the cell $\mathrm{CE}^{\star}$ from the list L2. If L2 is not empty, then go to Step 2, else stop.

Step 4: We have good BFS for the balanced transportation problem (P1). Now network simplex for the transportation problem can take over.

\section{Formulation of Linear Program}

Problem P2.

$\min C X$

s.t. 


$$
\begin{gathered}
A X=b \\
X \geq 0
\end{gathered}
$$

Matrices $A, X$ and $b$ are matrices of conformable dimensions ( $A$ is of the size $m \times n ; X$ is of size $n \times 1$; and $b$ is of size $m \times 1)$. It is to be noted that a BFS to problem $\mathrm{P} 2$ is associated with a matrix $B$ of size $m \times m$. Optimal BFS has at most " $m$ " positive entries in $X$ (that is of size $n \times 1$; such that $m<n$ ).

It is to be noted that Karmarkar's algorithm [3] to solve problem P2 gives a very good interior (feasible) point that has exactly "p" positive entries in $X 1$ such that $p>m$.

\section{The Proposed New Procedure PNP 2}

\section{PNP 2}

Step 1: It is to be noted that there are exactly $\mathrm{p} \mathrm{C} \mathrm{m}$ bases associated with the solution given to problem P2 by methods of [3]. Get one feasible basis (B1) with exactly " $m$ " columns in $\boldsymbol{X} \mathbf{1}$. Intuitively it is felt that this would be a good BFS.

Step 2: Choose other column (a2) in A that is not included in B1 such that a2 belongs to $X 1$. Set an $=\mathbf{a} 2$.

Step 3: Perform pivot with an as entering variable. It can be seen that an will enter the basis only if its relative cost co-efficient is strictly negative. It can be seen that the solution will improve or remain the same.

Step 4: If all columns associated with $X \mathbf{1}$ belonging to (p-m) are considered for entering variable, then stop; we have a good BFS and usual simplex can proceed further to get optimal solution; else choose other column in $X 1$ not considered earlier and call it an. Go to step 3.

We now have the optimal BFS to problem P2. It can be seen that this approach is different than the one given in [4].

\section{Conclusion}

Algorithms (that give very good solutions (non-BFS in general) in competitive times: transportation problem $\left(\mathrm{O}\left(\mathrm{n}^{3}\right)\right.$ \& simplex (for linear program) in $\mathrm{O}\left(\mathrm{n}^{5.5}\right)$ ) are available. We give a procedure that makes use for above; and gives very good BFS. Then control is given over to optimizing procedures (like Network Simplex (for transportation runs in $\mathrm{O}\left(\mathrm{n}^{3 \times} \log (\mathrm{n})\right.$ time) \& ordinary simplex procedure for linear program (exponential time complexity) to get optimal solutions. But since we start from a very good solution, it is hoped that the optimizing procedure will take significantly less time (compared to its worst case complexity given above). An empirical investigation has been undertaken and we will submit results as early as possible.

\section{References}

[1] Sharma, R.R.K. and Sharma, K.D. (2000) A New Dual Based Procedure for the Transportation Problem. European Journal of Operational Research, 122, 611-624. https://doi.org/10.1016/S0377-2217(99)00081-8 
[2] Sharma, R.R.K. and Prasad, S. (2003) Obtaining a Good Solution to the Uncapacitated Transportation Problem. European Journal of Operational Research, 144, 560-564. https://doi.org/10.1016/S0377-2217(01)00396-4

[3] Karmarkar, N. (1984) A New Polynomial Time Algorithm for Linear Programming. Combinatorica, 4, 373-395. https://doi.org/10.1007/BF02579150

[4] Ye, Y.Y. (1990) Recovering Optimal Basic Variables in Karmarkar's Polynomial Algorithm for Linear Program. Mathematics of Operations Research, 15, 564-572. https://doi.org/10.1287/moor.15.3.564

Submit or recommend next manuscript to SCIRP and we will provide best service for you:

Accepting pre-submission inquiries through Email, Facebook, LinkedIn, Twitter, etc. A wide selection of journals (inclusive of 9 subjects, more than 200 journals) Providing 24-hour high-quality service User-friendly online submission system Fair and swift peer-review system Efficient typesetting and proofreading procedure Display of the result of downloads and visits, as well as the number of cited articles Maximum dissemination of your research work

Submit your manuscript at: http://papersubmission.scirp.org/

Or contact ajor@scirp.org 